
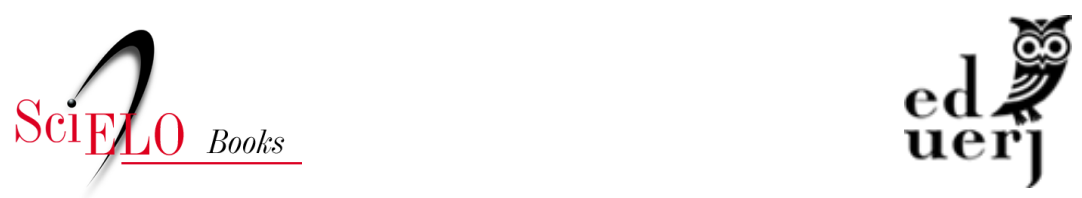

\title{
Prefácio: a política e a economia da política externa brasileira
}

\author{
Maria Regina Soares de Lima
}

\section{SciELO Books / SciELO Livros / SciELO Libros}

LIMA, M. R. S. Prefácio: a política e a economia da política externa brasileira. In: NERY, T. A política externa brasileira e a UNASUL: geopolítica e expansão do capitalismo brasileiro na América do Sul [online]. Rio de Janeiro: EDUERJ, 2021, pp. 19-25. Sociedade e política collection. ISBN: 978-65-87949-19-2.

https://doi.org/10.7476/9786587949192.0001.

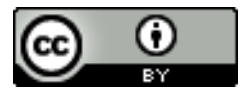

All the contents of this work, except where otherwise noted, is licensed under a Creative Commons Attribution 4.0 International license.

Todo o conteúdo deste trabalho, exceto quando houver ressalva, é publicado sob a licença Creative Commons Atribição 4.0.

Todo el contenido de esta obra, excepto donde se indique lo contrario, está bajo licencia de la licencia Creative Commons Reconocimento 4.0. 


\section{PREFÁCIO: A POLÍTICA E A ECONOMIA DA POLÍTICA EXTERNA BRASILEIRA}

Neste livro, Tiago Nery analisa a economia política da política externa brasileira e as tensões que dela derivam. Escrito originalmente como sua tese de doutorado, defendida no IESP/UERJ em 2015, o livro representa uma contribuição importante para um tema caro aos estudos sobre a inserção internacional do Brasil: a relação entre política externa e projeto de desenvolvimento. A tensão entre a dimensão política e econômica da política externa é examinada ao nível macro, sistêmico, da relação entre Estado e capitalismo; na dimensão regional, entre os projetos políticos de regionalismo e a expansão do capitalismo brasileiro na América do Sul; e no nível micro, nacional, entre as orientações de política externa das distintas coalizões políticas e o modelo de desenvolvimento dominante.

Com base nesta estrutura analítica, o autor apresenta um modelo de análise instigante para o estudo da política externa. Ao invés de avaliar os pesos explicativos de cada um dos determinantes localizados em três diferentes níveis de análise, ao modo do clássico de Kenneth Waltz, O Homem, o Estado e a Guerra, Tiago considera cada um deles como um contexto específico para compreender eventuais resultados que podem ser produzidos em outro nível de análise. Dessa forma, por exemplo, o contexto global em que há a inserção internacional do Brasil e sua política externa inclui sua condição de semiperiferia no sistema capitalista e, simultaneamente, sua localização espacial, geopolítica, no Hemisfério Ocidental, hegemonizado pelos EUA; tal condição já estabelece determinados parâmetros para 
a inserção internacional do Brasil e sua política externa. A interação entre o contexto regional e o nacional já é mais interdependente. Por seu tamanho, o Brasil é um fator para a configuração geopolítica e econômica regional e a sua conjuntura, ao mesmo tempo, impacta sobre os graus de liberdade da ação externa do país.

Contudo, o contexto é mutável e por isso sempre existe espaço para a agência da política externa, diante das contradições entre Estado e capitalismo e as especificidades do capitalismo nos países periféricos. Utilizando-se do conceito de conjunturas críticas, como momentos de transformações profundas em que os determinantes estruturais se afrouxam e abrem espaço para a ação dos agentes, pode-se dizer que o livro de Tiago Nery focaliza um desses momentos e suas implicações para a política externa brasileira. No plano global, a tensão permanente entre as duas lógicas de poder, a territorial e a do capital, gerou uma configuração de poder marcada pela desconcentração do ordenamento unipolar que vigorou logo após a Guerra Fria e a formação dos grandes países capitalistas periféricos representados no BRICS. Os anos 2000 constituíram, assim, uma janela de oportunidade para políticas externas mais assertivas na semiperiferia, simultaneamente à crise no capitalismo avançado e ao fracasso das experiências de reforma neoliberais na América Latina. É nesse quadro que se observa uma mudança de orientação política nos governos da América do Sul, com o início do ciclo progressista que vai abarcar praticamente todos os países da região, com a exceção mais clara da Colômbia. Aos anos 1990, quando as forças neoliberais eram hegemônicas, seguiu-se o ciclo de governos progressistas que, no Brasil, foi protagonizado pelos governos do PT.

As consequências da experiência de governos sustentados por duas coalizões ideologicamente distintas para o modelo de desenvolvimento e a política externa são amplamente examinadas no capítulo 3 do livro. A análise dos programas de governo de política externa do PSDB e do PT, no período de 1994 a 2014, evidencia as diferenças relevantes entre eles, excetuando-se a convergência com respeito à 
reforma do Conselho de Segurança das Nações Unidas. Contudo, os partidos conferem pesos distintos aos países do Norte, no caso do PSDB, enquanto o PT prioriza as relações Sul-Sul. Tiago Nery observa que a palavra "Sul" sequer é mencionada pelo PSDB. Divergências claras também se manifestam no que diz respeito às negociações da ALCA, com o último disposto a algum tipo de acordo e o PT frontalmente oposto à iniciativa. Contudo, é no plano regional que as diferenças são mais acentuadas. Citando Nery: "Enquanto o PSDB defende a flexibilização do Mercosul e a assinatura de acordos de livre comércio com outras regióes, o PT enfatiza a necessidade de fortalecer o bloco e ampliar a integração sul-americana, destacando a importância de organizaçóes como a Unasul".

Essas evidências apontam para três implicações importantes. A primeira delas é a vinculação explícita entre os respectivos modelos de desenvolvimento e a política externa. As diferenças acima apontadas refletem modelos distintos de cada uma das coalizóes - as reformas de mercado e a abertura econômica, no caso do PSDB, e o retorno do neodesenvolvimentismo, no do PT. Ademais, as questões regionais tendem a dividir mais as respectivas coalizões, e as diferenças domésticas acabam sendo projetadas para o nível regional. $\mathrm{O}$ autor chama a atenção para um dado importante. A partir de 2002, a chegada do $\mathrm{PT}$ ao poder deslocou o PSDB para uma posição de centro-direita no que diz respeito ao Mercosul, passando a defender sua flexibilização, aprofundamento de sua dimensão comercial e denúncia de uma alegada politização do processo de integração regional levado a cabo pelos governos do Partido dos Trabalhadores. Não poderia ser mais clara a interação entre o nível nacional e o contexto regional em que o último acaba sendo impactado pelas respectivas projeções das orientações políticas domésticas dos países da área e vice-versa.

A última implicação é, talvez, a mais importante porque diz respeito à discussão teórica e analítica em curso na literatura pertinente sobre a natureza da política externa como uma política pública, discussão que é objeto de uma extensa revisão bibliográfica pelo 
autor. A aceitação dessa propriedade da política externa passa pelo entendimento de que esta é a projeção externa do projeto de país e como tal reflete as ideias e os interesses da coalizão dominante, em um determinado momento, assim como é inevitável a sua politização e o conflito entre diferentes projetos de inserção internacional. Ainda que a política externa apresente algumas características particulares por atuar no ambiente externo e esteja sujeita a parâmetros condicionantes de sua atuação derivados de sua inserção particular na economia capitalista e localização geográfica na área de influência norte-americana, existe suficiente margem de manobra para que ela reflita sua base de apoio doméstico. Mas a descontinuidade de algumas políticas ao longo do tempo, como é o caso em particular do regionalismo sul-americano, analisada neste livro, é evidência suficiente que a política doméstica importa para a política externa.

Os dois últimos capítulos do livro estão voltados para a análise do padrão de regionalismo posto em prática pelos governos do PT - distinto daquele implementado pelos governos do PSDB - e para as tensões existentes entre o projeto político, consubstanciado na criação da Unasul, e a expansão regional do capitalismo brasileiro. Com relação à política sul-americana dos governos PT, Tiago ressalta que um de seus principais objetivos era a criação de uma forte identidade sul-americana, historicamente fragilizada pela inserção da região na área de influência geopolítica e econômica dos EUA. Por outro lado, a criação da Unasul tinha por base estabelecer um espaço institucional comum, com a participação de todos os países sul-americanos, capaz de superar a diversidade de modelos de inserção comercial, bem como projetos de política externa distintos e alinhamento político. Por essa razão, a organização foi concebida como uma entidade eminentemente política, o que provocou a crítica constante da oposição no Brasil. A expansão da fronteira econômica brasileira na região gerou uma tensão com o projeto da política regional. $\mathrm{O}$ autor analisa detidamente essa tensão e as ambiguidades expressas pelos nossos vizinhos. Os conflitos foram 
mais acentuados quando os investimentos se concentravam "em setores intensivos de recursos naturais ou na construção civil”. O ponto que distingue a expansão do capitalismo brasileiro é a seguinte observação do autor: "o país não exporta seus instrumentos de coerção para outros povos”, nem impõe condicionalidades políticas ou econômicas. Diplomatas equatorianos, em entrevistas realizadas, declararam preferir que sejam empresas brasileiras a investir no país desde que respeitem a legislação vigente.

$\mathrm{Na}$ verdade, naquele período o Brasil enfrentou o que a literatura especializada denomina o paradoxo do poder regional, em que os vizinhos, mesmo que reconheçam potenciais benefícios na cooperação com os poderes regionais, temem a dominação e as práticas coercitivas. A despeito da tensão e das ambiguidades, o saldo da política regional brasileira é amplamente favorável. A Unasul teve papel protagônico na mediação e solução de conflitos interestatais, contribuindo, dessa forma, para uma eventual consolidação da ideia de que os problemas regionais deveriam ser objeto da ação exclusiva dos países da região. Da perspectiva de vários de nossos vizinhos, os investimentos brasileiros trazem a experiência das empresas brasileiras e o financiamento de longo prazo, via BNDES, carentes no contexto nacional de muito deles.

Infelizmente as inovações dos governos do PT na política regional não tiveram tempo de se consolidar, sendo bruscamente interrompidas em 2016 com o abandono dos setores empresarias da coalizão de apoio dos governos do partido, o impedimento de Dilma Rousseff, a chegada ao poder do governo Temer e a eleição de Jair Bolsonaro, em 2018. Na conclusão, Tiago Nery analisa o retrocesso na política brasileira desde então, agravado após a inauguração do governo de extrema-direita de Bolsonaro, o retorno da lógica da aquiescência na política externa, o refluxo dos investimentos internacionais de empresas brasileiras envolvidas nos processos da Lava Jato e o desmonte de toda a arquitetura institucional sul-americana, construída nos governos do PT. 
Diante do atual retrocesso brasileiro, o livro de Tiago Nery é uma fonte valiosa de análise desse período de inovações significativas na política externa, nos planos global e regional, cuja cultura estratégica pautou-se pelo mote da autonomia diante de um contexto internacional assimétrico e desfavorável aos interesses do país.

Algumas questões para reflexão posterior para aqueles interessados em temas de política externa derivam diretamente da excelente análise de Tiago Nery sobre a relação entre modelo de desenvolvimento, coalizões políticas e política externa. Até a crise do modelo de inserção internacional do Brasil, ao final dos anos 1980, com base na industrialização por substituição de importações, observou-se a hegemonia de uma cultura estratégica comum com base em duas ideias-chave: autonomia e desenvolvimento. Como argumenta Nery, durante a vigência do projeto nacional-desenvolvimentista, a dimensão estrutural se sobrepôs aos elementos de natureza político-ideológica, responsável pela alegada continuidade da política externa. À crise daquele modelo nos anos 1990, seguiu-se uma guinada significativa na economia política interna e externa com a hegemonia das ideias neoliberais e o fim do consenso desenvolvimentista entre setores das elites econômica, política e burocrática. Essa hegemonia durou pouco mais de uma década e foi substituída com a chegada ao poder de uma coalizão reunida em torno dos governos do PT, aglutinando setores políticos de esquerda e centro-esquerda nos partidos, burocracias públicas, movimentos sociais, setores empresariais e sindicatos. Este é o momento estudado neste livro e talvez um dos mais ricos em inovações na política externa. Mas, assim como na década de 1990, iniciativas de política externa não contaram com o apoio de todos os setores de elite, razão pela qual em ambos os períodos a inserção internacional do país foi objeto de disputa política entre forças políticas e ideológicas antagônicas. A baixa coesão das elites e a frágil penetração na sociedade mais ampla contribuíram para que muitas das inovações em política externa desse último ciclo político não se institucionalizassem. $\mathrm{Na}$ atualidade, vivemos um novo ciclo 
político à direita e o retrocesso de praticamente todas as iniciativas do passado recente.

A experiência histórica de outros países que ascenderam na estratificação internacional demonstra que a coesão das elites e a hegemonia de uma cultura estratégica comum nas elites e na sociedade mais ampla são condições necessárias para tal emergência. Essa constatação pode ser um consolo para aqueles que, repudiando o presente status quo, projetam, a curto e médio prazos, o tempo de duração da política de aquiescência do atual governo. Mas, sobretudo, lança uma interrogação para os estudiosos e praticantes da política internacional brasileira: por que depois da crise do modelo nacional-desenvolvimentista não mais se constituiu a situação de hegemonia de uma cultura estratégica comum na sociedade e na política brasileiras? A leitura deste livro fornece pistas instigantes para se responder à essa questão.

Maria Regina Soares de Lima Professora do Instituto de Estudos Sociais e Políticos da UERJ - IESP/UERJ Rio de Janeiro, julho de 2019 